\title{
Phylogenetic Analysis of Baculovirus Isolates from Diseased Insects in Southern Vietnam
}

\author{
Nguyen Thi Phuong Thao', Nguyen Thi Thuy1, Nguyen Khac Duy1', Doan Chinh Chung2, \\ Do Minh $\mathrm{Si}^{2}$, Le Thanh Long ${ }^{*}$ \\ ${ }^{1}$ Institute of Tropical Biology, Vietnam Academy of Science and Technology, Ho Chi Minh City, Vietnam \\ ${ }^{2}$ University of Science, Ho Chi Minh City, Vietnam \\ Email: ${ }^{*}$ lelong2510@gmail.com
}

Received 8 July 2014; revised 7 August 2014; accepted 28 August 2014

Copyright (C) 2014 by authors and Scientific Research Publishing Inc.

This work is licensed under the Creative Commons Attribution International License (CC BY). http://creativecommons.org/licenses/by/4.0/

(c) (i) Open Access

\section{Abstract}

The aim of this study was to investigate the molecular identification and assess the genetic relationship of baculovirus isolated from Southern Vietnam. The diseased insect samples were collected from the different fields. The partial sequence of 450 base pairs of lef- 8 gene was amplified and sequenced to assess the genetic variations of baculovirus isolates specific for Spodoptera litura, Helicoverpa zea, and Helicoverpa armigera. The sequences alignment demonstrated that Helicoverpa zea specific isolates exhibited six single nucleotide polymorphic sites. Whereas, twenty five single polymorphic sites were found in Spodoptera litura specific isolates. Thus, Spodoptera litura specific isolates were higher polymorphic than Helicoverpa zea specific isolates. The genetic distance analyses showed that the distance between Vietnamese baculovirus isolates and Group II Alphabaculovirus isolates was lower than other Baculovirus groups. The phylogeny of Vietnamese isolates in relation to other baculovirus isolates was also determined using partial sequences of lef-8 gene. The phylogenetic tree placed all Vietnamese isolates in Group II Alphabaculovirus, where seven Vietnamese Helicoverpa zea specific isolates were most closely related to Helicoverpa zea SNPV, fourteen Vietnamese Spodoptera litura specific isolates were located with Spodoptera litura NPV-G2 in one clade and a Vietnamese Helicoverpa armigera isolate was appeared to be closely related to Helicoverpa armigera SNPV-NNg1, Helicoverpa armigera NPV-C1, Helicoverpa armigera NPV-G4.

\section{Keywords}

Baculovirus, Helicoverpa armigera, Helicoverpa zea, Lef-8 Gene, Phylogeny, Spodoptera litura

\footnotetext{
${ }^{*}$ Corresponding author.
} 


\section{Introduction}

Baculoviruses are a very diverse group of viruses with double-stranded, circular, supercoiled genomes, with sizes varying from about 80 to over $180 \mathrm{~kb}$ and that encode between 90 and 180 genes [1]. The genome is packaged in rod-shaped nucleocapsids that are $230-385 \mathrm{~nm}$ in length and $40-60 \mathrm{~nm}$ in diameter [2] [3]. In the most well characterized baculoviruses, the virions are present as two types, occluded virions and budded virions. Baculoviruses have been reported from a variety of different species of invertebrates. However, the only well documented hosts are Diptera, Hymenoptera, and Lepidoptera. The Baculoviridae family is divided into four genera: Alphabaculovirus (lepidopteran-specific nucleopolyhedroviruses), Betabaculovirus (lepidopteran-specific Granuloviruses), Gammabaculovirus (hymenopteran-specific nucleopolyhedroviruses) and Deltabaculovirus (dipteran-specific nucleopolyhedroviruses) [4]. PCR-base method has been useful tools to identify baculovirus isolates. The late expression factor 8 (lef-8) was a highly conserved DNA region which was used as targets for degenerate PCR primers [5]. The lef-8 gene encodes for a subunit of the baculovirus RNA polymerase, which initiates transcription from late and very late promoters [6]. Lef-8 was previously suitable for studying baculovirus phylogeny [7].

Vietnam is a tropical country with $1,687,000$ ha for fruit, treenut and vegetable crops [8]. These are favorable natural conditions for insect specific baculoviruses. However, no study of distribution and genetic variation of baculovirus in Vietnam have been conducted. In present study, partial lef-8 gene amplification and sequencing was applied to identify the distribution and genetic relationship of baculovirus in Southern Vietnam and be compared to the other baculovirus isolates.

\section{Materials and Methods}

\subsection{Insects and Virus Collection}

The diseased insects were collected from Ho Chi Minh City, Binh Duong Province, Ninh Thuan Province (Figure 1). Fourteen Spodoptera specific isolates were obtained from cabbage. Seven Helicoverpa zea specific baculovirus isolates were obtained from tomato and corn. One Helicoverpa armigera isolate was obtained from tomato (Table 1).

\subsection{DNA Extraction from Diseased Insects}

DNA extractions of samples of baculovirus infected insects were performed using DNeasy Tissue Kit (69504, Qiagen) according to manuals of the manufacturer. These samples were kept frozen at $-20^{\circ} \mathrm{C}$.

\subsection{Viral DNA Amplification by PCR}

The amplification of partial lef-8 gene was performed using degenerate primers [9] (Table 2). PCR was performed in a final volume of $50 \mu \mathrm{l}$ containing $5 \mu \mathrm{l} \mathrm{10 \times} \mathrm{PCR} \mathrm{Buffer} \mathrm{(P2192,} \mathrm{Sigma),} 1.5 \mathrm{mM} \mathrm{MgCl}, 200 \mu \mathrm{M}$ dNTP (D7295, Sigma), 0.05 units/ $\mu$ Taq DNA Polymerase (D6677, Sigma), $0.5 \mu$ M Forward and Reverse Primer. PCR cycle was performed under the following conditions: one cycle of DNA denaturation at $94^{\circ} \mathrm{C}$ in 5 min; 40 cycles at $94^{\circ} \mathrm{C}$ in $30 \mathrm{~s}$; annealing at $48^{\circ} \mathrm{C}$ in $45 \mathrm{~s}$; extension at $72^{\circ} \mathrm{C}$ in $45 \mathrm{~s}$; final extension at $72^{\circ} \mathrm{C}$ in $10 \mathrm{~min}$. A single band was visualized following electrophoresis of the reaction product in a $1 \%$ agarose gel.

\subsection{Phylogenetic Analyses}

PCR products were purified using ExoSAP-IT PCR Clean up kit and used as sequencing templates. The nucleotide sequences were determined using the 3730XL DNA Analyzer. The comparison of lef-8 sequences was performed for 22 Vietnamese baculovirus isolates and other isolates from Genbank in Table 3 [10]. The lef-8 sequences were aligned using CLUSTAL W [11]. Tamura \& Nei model was used as a genetic distance model. Neighbor-joining method was applied for phylogenetic construction [12]. Bootstrap analyses (using 1000 replications) were used to assess the confidence in branching order.

\section{Results and Discussion}

In this study, the amplification of lef-8 gene was successful for 22 isolates which were collected from various 


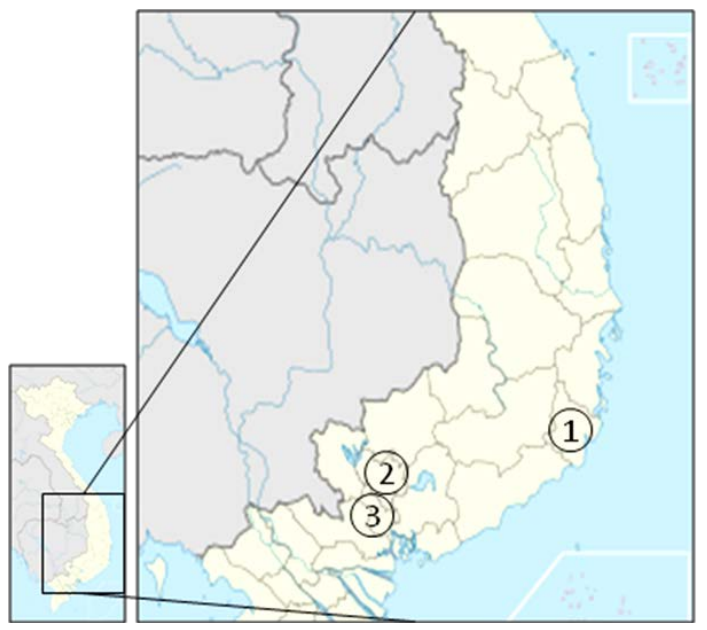

Figure 1. Geographical locations of collecting diseased insects. 1: Ninh Thuan Province, 2: Binh Duong Province, 3: Ho Chi Minh City.

Table 1. Baculovirus isolates with their host insect, host plant and sources.

\begin{tabular}{ccccc}
\hline No. & Isolate & Host insect & Host plant & Collection area \\
\hline 1 & Spli-HCM1 & Spodoptera litura & Cabbage & Ho Chi Minh City \\
2 & Spli-HCM2 & Spodoptera litura & Cabbage & Ho Chi Minh City \\
3 & Spli-HCM3 & Spodoptera litura & Cabbage & Ho Chi Minh City \\
4 & Spli-HCM4 & Spodoptera litura & Cabbage & Ho Chi Minh City \\
5 & Spli-NT1 & Spodoptera litura & Cabbage & Ninh Thuan Province \\
6 & Spli-NT2 & Spodoptera litura & Cabbage & Ninh Thuan Province \\
7 & Spli-NT3 & Spodoptera litura & Cabbage & Ninh Thuan Province \\
8 & Spli-NT4 & Spodoptera litura & Cabbage & Ninh Thuan Province \\
9 & Spli-NT5 & Spodoptera litura & Cabbage & Ninh Thuan Province \\
10 & Spli-NT6 & Spodoptera litura & Cabbage & Ninh Thuan Province \\
11 & Spli-NT7 & Spodoptera litura & Cabbage & Ninh Thuan Province \\
12 & Spli-BD1 & Spodoptera litura & Cabbage & Binh Duong Province \\
13 & Spli-BD2 & Spodoptera litura & Cabbage & Binh Duong Province \\
14 & Spli-BD3 & Spodoptera litura & Cabbage & Binh Duong Province \\
15 & Hear-BD & Helicoverpa armigera & Tomato & Binh Duong Province \\
16 & Hz-HCM1 & Helicoverpa zea & Tomato & Ho Chi Minh City \\
17 & Hz-HCM2 & Helicoverpa zea & Tomato & Ho Chi Minh City \\
18 & Hz-HCM3 & Helicoverpa zea & Tomato & Ho Chi Minh City \\
19 & Hz-BD1 & Helicoverpa zea & Corn & Binh Duong Province \\
20 & Hz-BD2 & Helicoverpa zea & Corn & Binh Duong Province \\
21 & Hz-BD3 & Helicoverpa zea & Corn & Binh Duong Province \\
22 & Hz-BD4 & Helicoverpa zea & Binh Duong Province \\
\hline
\end{tabular}

Table 2. Primer pairs used for amplification.

\begin{tabular}{ccc}
\hline Primers & Sequence $^{\mathrm{a}}$ & Size $^{(\text {base pairs) }}{ }^{\mathrm{b}}$ \\
\hline L8F2 & gtaaaacgacggccagtNNNACNRCNGARGAYCC & 450 \\
L8R2 & aacagctatgaccatgMMNCCYTTYTGNCCRTG & \\
\hline
\end{tabular}

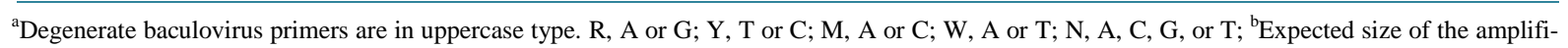
cation product. 
Table 3. Accession numbers of baculovirus isolates.

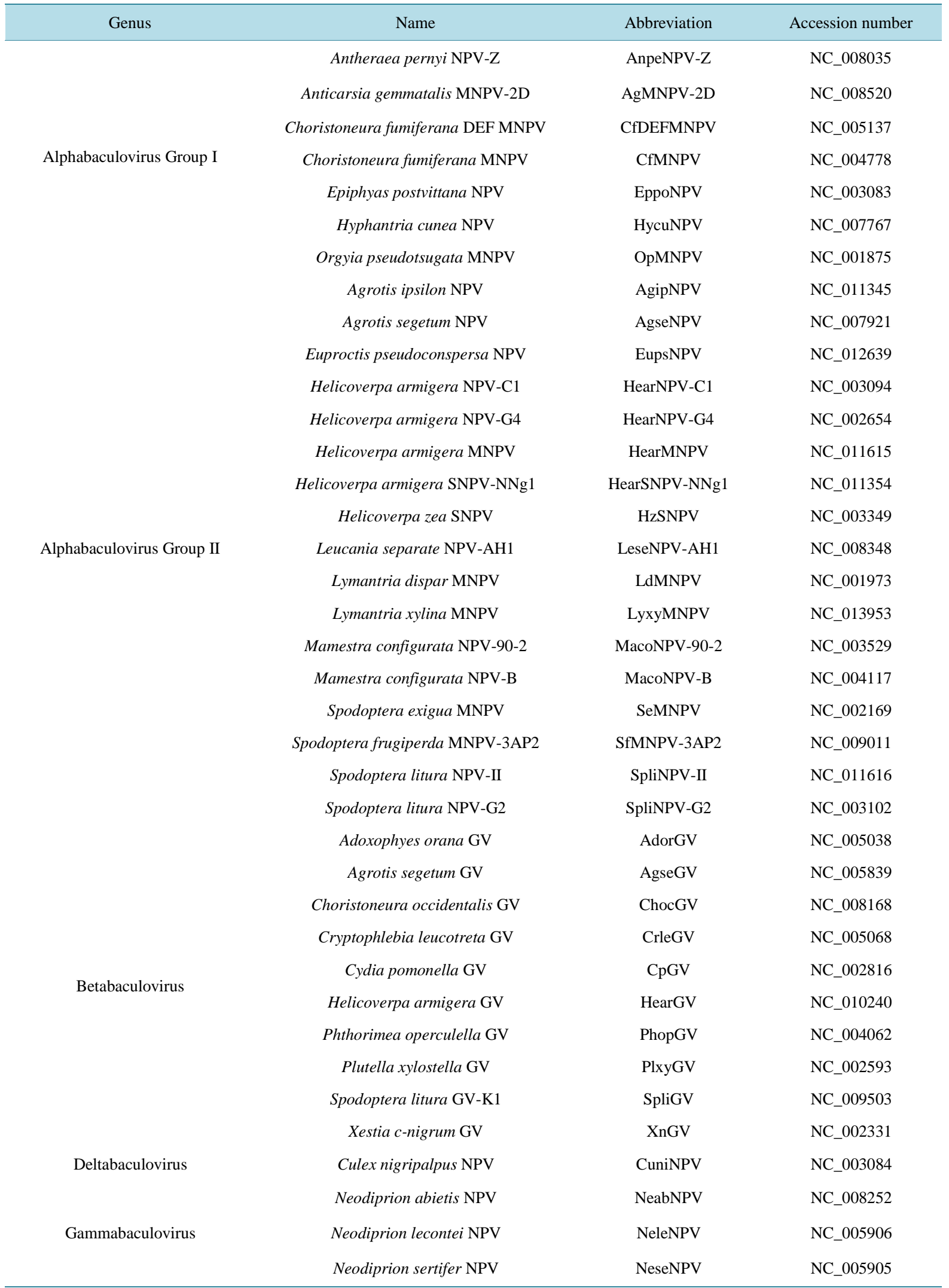


areas of Southern Vietnam. The genetic polymorphisms among 22 baculoviruse isolates were indentified and analyzed using lef-8 gene obtained from degenerated primers. A fragment of 450 base pairs was amplified. However, a nucleotide sequence of 335 base pairs was used for the analysis due to the higher quality and reliability of sequencing after manual edition. These baculoviruse isolates were distributed in 2 main groups including 14 Spodoptera litura specific isolates and 7 Helicoverpa zea specific isolates. The bases proportion was different between two types of isolates. The base proportion for Spodoptera litura specific isolates from Vietnam was $19.2 \%$ of thymine, $20.9 \%$ of cytosine, $34.6 \%$ of adenine and $25.3 \%$ of guanine. The base proportion for $\mathrm{He}$ licoverpa zea specific isolates from Vietnam was $18.8 \%$ of thymine, $23.8 \%$ of cytosine, $36.4 \%$ of adenine and $21 \%$ of guanine.

The lef-8 alignment exhibited six single polymorphic sites among Helicoverpa zea specific isolates where the Hz-BD1, Hz-BD2, Hz-BD3, Hz-BD4 isolates differed from the remaining isolates by a $\mathrm{G}$ to A transition at position 1993 of lef-8 gene. The Hz-BD1 and Hz-BD3 isolates also exhibited a G to A transition at position 1972 of lef-8 gene. Whereas, the Hz-HCM2 and Hz-BD2 isolates exhibited an A to G transition at position 1908 of lef-8 gene.

The field baculovirus isolates which were collected from various crops and geographic locations commonly expressed genetic variations [13] [14]. In this study, the Vietnamese Helicoverpa zea specific isolates from Ho Chi Minh City were genetically different from Binh Duong Province in the number of variable positions of lef-8 gene. The alignment revealed 3 variable positions of Hz-HCM1, Hz-HCM2 and Hz-HCM3 isolates at position 1895, 1896 and 1908 in lef-8 gene. Conversely, the Hz-BD1, Hz-BD2, Hz-BD3 and HzBD4 isolates exhibited 6 variations at position 1989, 1896, 1908, 1972, 1993 and 2033 in lef-8 gene.

In contrast to Helicoverpa zea specific isolates, the Spodoptera litura specific isolates were highly variable, displaying a total of twenty five single polymorphic sites, suggesting that Spodoptera litura specific isolates were high polymorphic than Helicoverpa zea specific isolates.

The sequences of Spodoptera litura specific isolates and Helicoverpa zea specific isolates were compared to SpliNPV-G2 [15] and HzSNPV [9], respectively. The lef-8 gene of fourteen Spodoptera litura specific isolates were aligned with SpliNPV-G2 and showed the identity greater than $96 \%$. The lef-8 gene of seven Helicoverpa zea specific isolates were aligned with HzSNPV and showed the identity greater than 98\%.

The genetic distances with in Spodoptera litura specific isolates and Helicoverpa zea specific isolates were $0.101 \pm 0.065$ and $0.053 \pm 0.022$, respectively, suggesting that the Helicoverpa zea specific isolates were lower genetic variable than Spodoptera litura specific isolates. The genetic distance between groups analyses also showed that the distance between Spodoptera litura specific isolates with Group II Alphabaculovirus were higher than Helicoverpa zea $(0.234 \pm 0.181$ and $0.071 \pm 0.044$, respectively), indicating inter-specific divergence in Spodoptera litura specific isolates. Thus, the partial sequence of the lef-8 gene of $335 \mathrm{bp}$ used in this study could be applied to discriminate Helicoverpa zea specific isolates and Spodoptera litura specific isolates. The genetic distances between Vietnamese isolates were lower than other distances from other groups (Table 4). This result supported for a close genetic relationship between Vietnamese isolates and Group II Alphabaculovirus.

The neighbor-joining tree was applied to assess the phylogenetic relationship of Vietnamese isolates in Baculoviridae family using partial lef-8 gene (Figure 2). The phylogram was rooted using sequence of NeseNPV, which was clustered with other isolates from Gammabaculovirus in one clade (NeabNPA isolate and NeleNPV isolate). The other major clades included the Betabaculovirus and Group I Alphabaculovirus with $46 \%$ bootstrap value and 67\% bootstrap value, respectively. The Group I Alphabaculovirus originated as an ancestral Group II Alphabaculovirus [16]. All Vietnamese isolates belonged to Group II Alphabaculovirus which appeared paraphyletic as a sister clade to Group I [14]. The Vietnamese isolates formed several smaller clades within Group II Alphabaculovirus. Seven Vietnamese Helicoverpa zea specific isolates were located with HzSNPV isolate. The Helicoverpa zea cluster exhibited two groups: one containing 4 isolates from Binh Duong Province (from HzBD1 to Hz-BD4) and the other with 3 isolates from Ho Chi Minh City (from Hz-HCM1 to Hz-HCM3). This clade was supported by high bootstrap value of 91\% (Figure 2). The Vietnamese Hear-BD isolate was found in Group II and appeared to be closely related to HearSNPVNNg1, HearNPV-C1 and HearNPV-G4 with 52\% bootstrap value. Fourteen Vietnamese Spodoptera litura specific isolates were located with SpliNPV-G2 isolate with $78 \%$ bootstrap value, suggesting that these isolates have a close genetic relationship to SpliNPV-G2. There were no subheadings among Spodoptera litura specific isolates from Ho Chi Minh City, Ninh Thuan Province and Binh Duong Province. 
Table 4. Matrix of Tamura \& Nei genetic distance among baculovirus isolates. Lower triangular matrix values were mean genetic distances, upper triangular matrix values were standard errors.

\begin{tabular}{cccccccc}
\hline & Spodoptera (Vietnam) & Helicoverpa (Vietnam) & Alpha_1 & Alpha_2 & Beta & Delta & Gamma \\
\hline Spodoptera (Vietnam) & & 0.272 & 0.352 & 0.181 & 0.371 & 0.712 & 0.720 \\
Helicoverpa (Vietnam) & 0.379 & & 0.236 & 0.044 & 0.281 & 0.767 & 0.560 \\
Alpha_1 & 0.472 & 0.343 & & 0.190 & 0.360 & 0.524 & 0.732 \\
Alpha_2 & 0.234 & 0.071 & 0.261 & & 0.180 & 0.654 & 0.596 \\
Beta & 0.476 & 0.399 & 0.412 & 0.258 & & 0.687 & 0.550 \\
Delta & 0.873 & 0.915 & 0.681 & 0.760 & 0.709 & & 1.004 \\
Gamma & 0.717 & 0.639 & 0.683 & 0.600 & 0.503 & 0.934 & \\
\hline
\end{tabular}

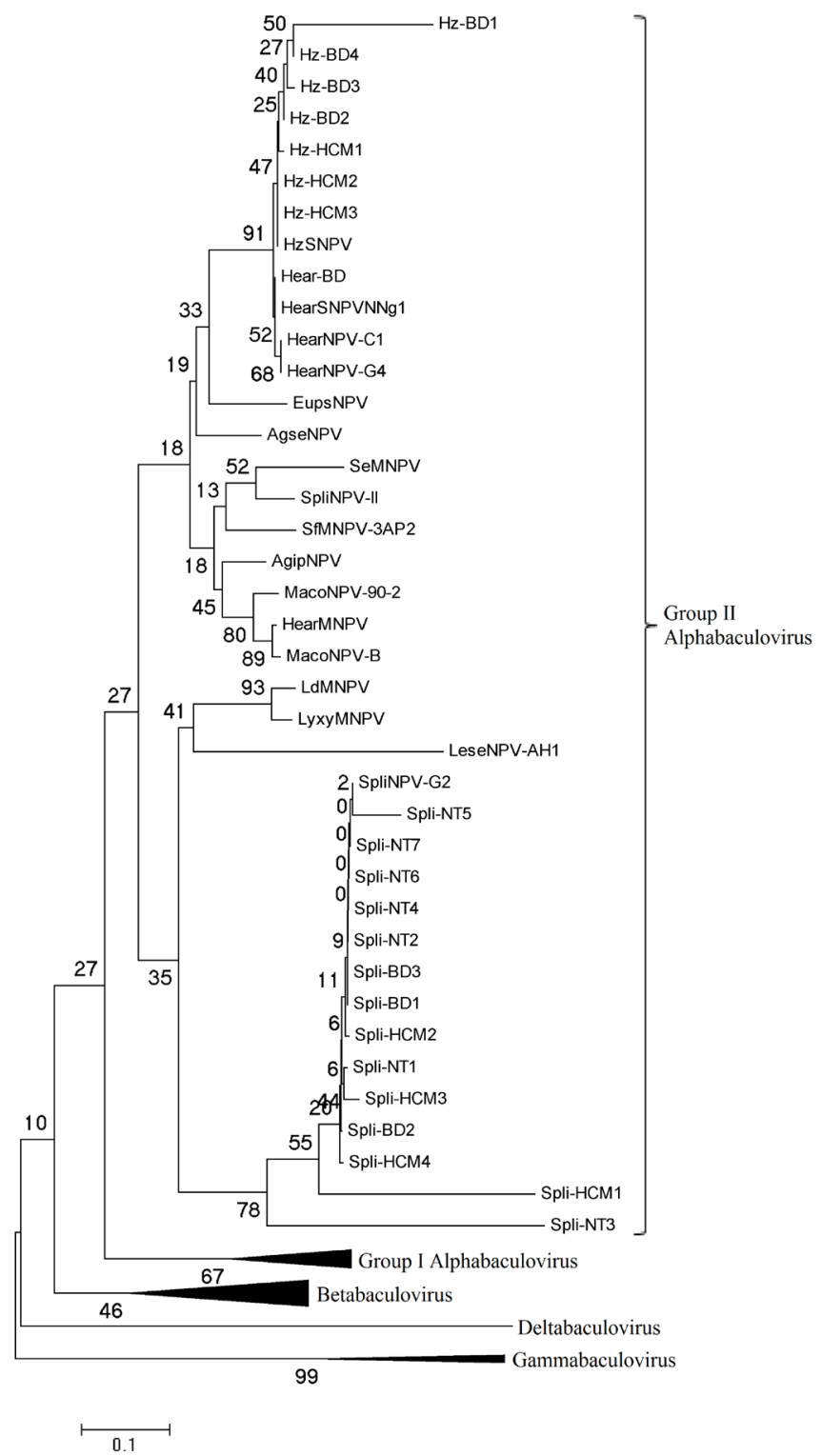

Figure 2. Phylogenetic tree constructed from partial lef-8 sequences of baculovirus isolates by the neighbor-joining analysis method. Bootstrap resampling was done 1000 times, and resulting bootstrap values are shown on the corresponding branches. 


\section{Acknowledgements}

This study was supported by Department of Science and Technology Ho Chi Minh city, Vietnam.

\section{References}

[1] Rohrmann, G.F. (2011) Baculovirus Molecular Biology. 2nd Edition, National Library of Medicine (US), National Center for Biotechnology Information, Bethesda, 9-10.

[2] Lung, O.Y., Cruz, A.M. and Blissard, G.W. (2003) Ac23, an Envelope Fusion Protein Homolog in the Baculovirus Autographa californica Multicapsid Nucleopolyhedrovirus, Is a Viral Pathogenicity Factor. Journal of Virology, 77, 328-339. http://dx.doi.org/10.1128/JVI.77.1.328-339.2003

[3] Roncarati, R. and Knebel-Morsdorf, D. (1997) Identification of the Early Actin-Rearrangement-Inducing Factor Gene, Arif-1, from Autographa californica Multicapsid Nuclear Polyhedrosis Virus. Journal of Virology, 71, 7933-7941.

[4] Jehle, J.A., Blissard, G.W., Bonning, B.C., Cory, J.S., Herniou, E.A., Rohrmann, G.F., Theilmann, D.A., Thiem, S.M. and Vlak, J.M. (2006) On the Classification and Nomenclature of Baculoviruses: A Proposal for Revision. Archives of Virology, 151, 1257-1266. http://dx.doi.org/10.1007/s00705-006-0763-6

[5] Lange, M., Wang, H.L., Hu, Z.H. and Jehle, J.A. (2004) Towards a Molecular Identification and Classification System of Lepidopteran-Specific Baculoviruses. Virology, 325, 36-47. http://dx.doi.org/10.1016/j.virol.2004.04.023

[6] Guarino, L.A., Xu, B., Jin, J.P. and Dong, W. (1998) A Virus-Encoded RNA Polymerase Purified from BaculovirusInfected Cells. Journal of Virology, 72, 7985-7991.

[7] Herniou, E.A., Luque, T., Chen, X., Vlak, J.M., Winstanley, D., Cory, J.S. and O’Reilly, D.R. (2001) Use of Whole Genome Sequence Data to Infer Baculovirus Phylogeny. Journal of Virology, 75, 8117-8126.

http://dx.doi.org/10.1128/JVI.75.17.8117-8126.2001

[8] Food and Agriculture Organization of the United Nations (2013) World Food and Agriculture. FAO Statistical Yearbook, Rome, 165-168.

[9] Herniou, E.A., Olszewski, J.A., O’Reilly, D.R. and Cory, J.S. (2004) Ancient Coevolution of Baculoviruses and Their Insect Hosts. Journal of Virology, 78, 3244-3251. http://dx.doi.org/10.1128/JVI.78.7.3244-3251.2004

[10] Solange, A.B.M., Matias, J.G., Mariano, N.B. and Pablo, D.G. (2011) Baculovirus: Molecular Insights on Their Diversity and Conservation. International Journal of Evolutionary Biology, 2011, 1-15.

[11] Tamura, K., Peterson, D., Peterson, N., Stecher, G., Nei, M. and Kumar, S. (2011) MEGA5: Molecular Evolutionary Genetics Analysis Using Maximum Likelihood, Evolutionary Distance, and Maximum Parsimony Methods. Molecular Biology and Evolution, 28, 2731-2739. http://dx.doi.org/10.1093/molbev/msr121

[12] Saitou, N. and Nei, M. (1987) The Neighbor-Joining Method: A New Method for Reconstructing Phylogenetic Trees. Molecular Biology and Evolution, 4, 406-425.

[13] Li, L., Li, Q., Willis, L.G., Erlandson, M., Theilmann, D.A. and Donly, C. (2005) Complete Comparative Genomic Analysis of Two Field Isolates of Mamestra configurata Nucleopolyhedrovirus-A. Journal of General Virology, 86, 91-105. http://dx.doi.org/10.1099/vir.0.80488-0

[14] Craveiro, S.R., Melo, F.L., Ribeiro, Z.M., Ribeiro, B.M., Báo, S.N., Inglis, P.W. and Castro, M.E. (2013) Pseudoplusia Includens Single Nucleopolyhedrovirus: Genetic Diversity, Phylogeny and Hypervariability of the Pif-2 Gene. Journal of Invertebrate Pathology, 114, 258-267. http://dx.doi.org/10.1016/j.jip.2013.08.005

[15] Pang, Y., Yu, J. and Wang, L. (2001) Sequence Analysis of the Spodoptera litura Multicapsid Nucleopolyhedrovirus Genome. Virology, 287, 391-404. http://dx.doi.org/10.1006/viro.2001.1056

[16] Jiang, Y., Deng, F., Rayner, S., Wang, H. and Hu, Z. (2009) Evidence of a Major Role of GP64 in Group I Alphabaculovirus Evolution. Virus Research, 142, 85-91. http://dx.doi.org/10.1016/j.virusres.2009.01.015 
Scientific Research Publishing (SCIRP) is one of the largest Open Access journal publishers. It is currently publishing more than 200 open access, online, peer-reviewed journals covering a wide range of academic disciplines. SCIRP serves the worldwide academic communities and contributes to the progress and application of science with its publication.

Other selected journals from SCIRP are listed as below. Submit your manuscript to us via either submit@scirp.org or Online Submission Portal.
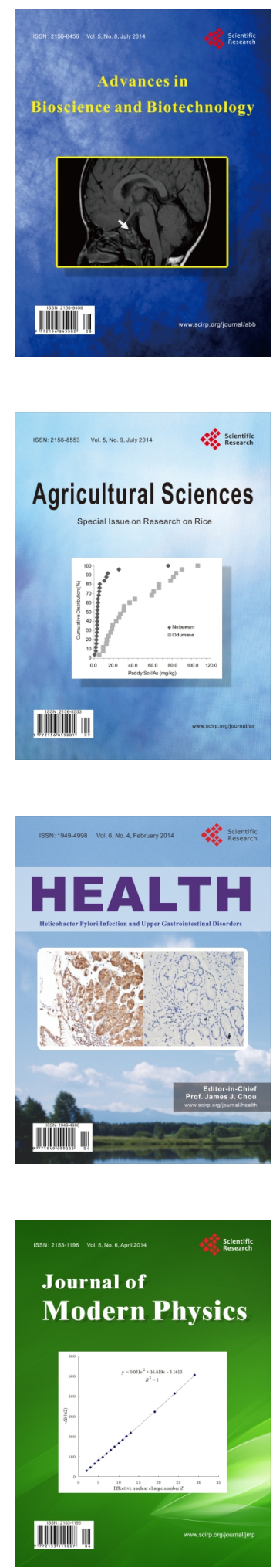
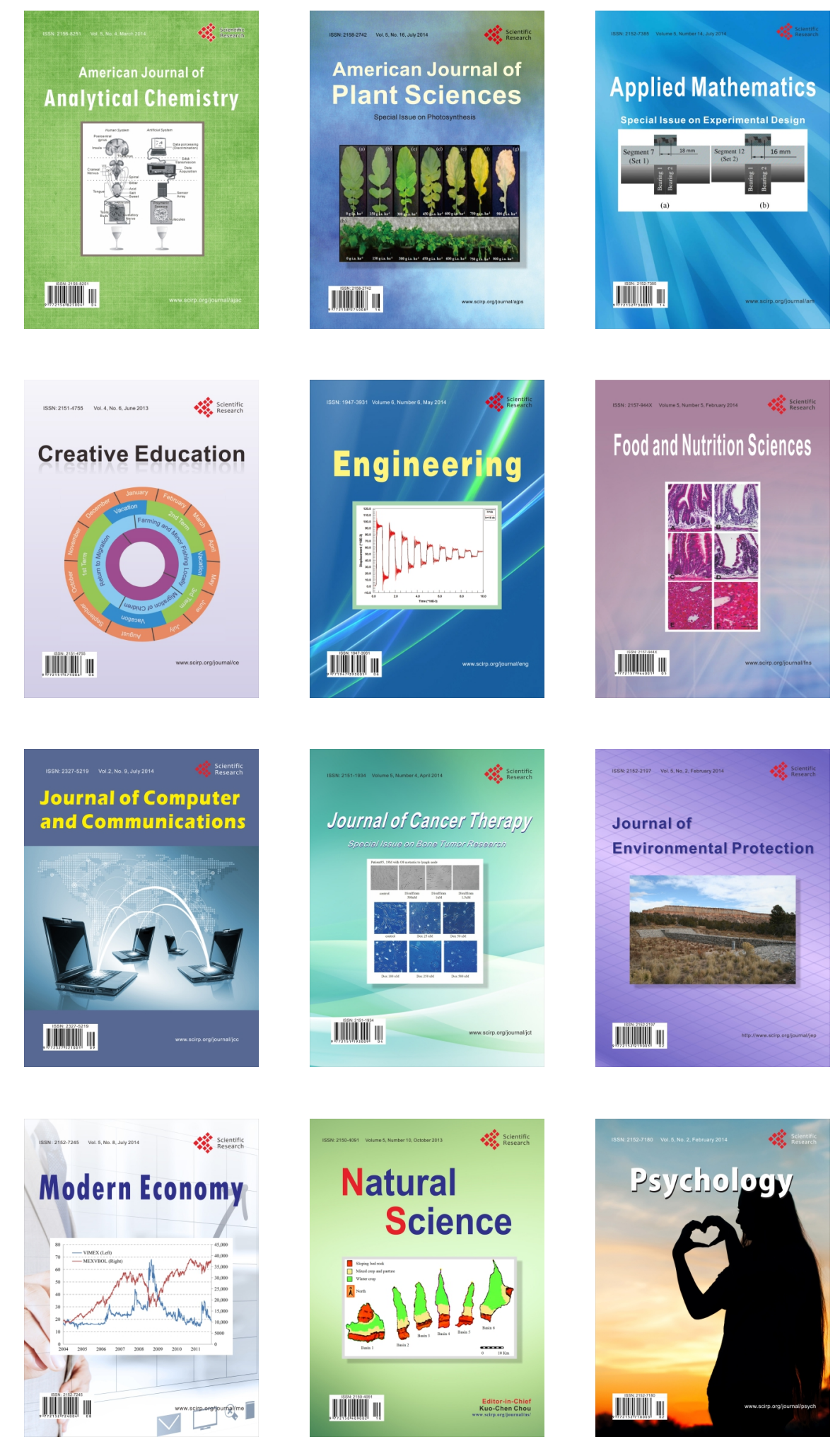